\title{
A Grande Guerra e a América Latina
}

\author{
La Gran Guerra y la América Latina \\ The Great War and Latin America \\ La Grande Guerre et l’Amérique latine
}

Norberto Ferreras ${ }^{[1]}$

\section{COMPAGNON, Olivier. L'adieu à l'Europe. L'Amerique latine et la Grande Guerre (Argentine et Brésil, 1914-1939). Paris: Fayard, 2013.394 p.}

\begin{abstract}
$\Lambda$ relação entre América Latina e Europa já foi estudada muitas vezes,algumas a partir do ponto de vista da influência e outras,da rejeição. Não são poucos os autores que podem ser arrolados entre os especialistas do tema em ambas as perspectivas. $\mathrm{O}$ mesmo poderíamos dizer da Grande Guerra (1914-1918),principalmente numa data tão marcante quanto o centenário. Sem ir muito longe, no Brasil vários seminários foram realizados e deles resultaram (ou virão a resultar) livros e artigos. As datas comemorativas sempre geram ondas expansivas de bibliografia relacionada ao tema em questão e essas ondas criam uma massa de títulos que em alguns casos será rapidamente esquecida junto com as efemérides. Esse não é o caso do livro aqui resenhado.

No livro L'adieu à l'Europe..., Compagnons e propõe a analisar o período de entre guerras que já tinha analisado anteriormente do ponto de vista das circulações entre América e Europa, quando estudou os vínculos entre o catolicismo e a reconfiguração do nacionalismo latino-americano. Acompanhando a história das circulações e dos contatos - a "história conectada" -, vemos que ele tanto aborda o vínculo intrínseco estabelecido entre Europa e América, quanto analisa o imaginário e a imagem criada pela Grande Guerra nos países latino-americanos, mais especificamente, na Argentina e no Brasil. Ao mesmo tempo, devemos entender este livro como um ensaio de história global, acompanhando a terminologia de época. Este é um estudo que, utilizando as fronteiras nacionais, as ultrapassa e redefine. Coloca-nos a pensar sobre o impacto de uma guerra europeia lutada em frentes que ultrapassaram os países e os continentes, que estabeleceram coalisões definidas pela afinidade política e econômica antes que pela territorialidade e que levou à reflexão
\end{abstract}


acerca do modelo cultural e político europeu iluminista e de progresso constante. A Grande Guerra colocou os paradigmas existentes em xeque e fez seus contemporâneos e descendentes imediatos refletirem sobre o rumo da civilização ocidental e sua primazia, trazendo à tona outras possibilidades e alternativas desde o regional, rivalizando com o farol universal que pretendia ser Europa.

O livro propõe-se a estudar a Grande Guerra de uma perspectiva original. Nãoenfoca os fatos, nem volta àtentativa de revisão dos impactos europeus ou coloniais da guerra. Sem desconhecê-los, analisá-los não é o objetivo principal. O tema é a relação entre Europa e América Latina em um momento-chave para a história regional e para pensar a história latino-americana. O período em questão dialoga com a história global, mas é umaépoca de redefinições da latinidade e, ao mesmo tempo e num nível mais profundo, da nacionalidade. $\mathrm{O}$ autor tentará estabelecer as relações e influências da Grande Guerra no imediato e nas reflexões sobre o vínculo americano com a Europa.

\section{A Grande Guerra colocou os paradigmas existentes em xeque e fez seus contemporâneos e descendentes imediatos refletirem sobre o rumo da civilização ocidental}

Para desenvolver a sua hipótese, Compagnon divide o seu trabalho em três partes. A primeira parte, titulada "Da guerra europeia à guerra americana", trata de como a guerra europeia é também uma guerra americana. A preocupação é pelo impacto mais imediato do conflito, como o mesmo levou ao posicionamento dos grandes atores políticos do período, principalmente como se portaram as elites políticas em uma conjuntura de redefinição de alianças, modelos e paradigmas. O livro estabelece um recorte nos dois grandes países da América do Sul, a Argentina e o Brasil; isso não implica negligenciar as linhas de força daqueles países que, de forma semelhante e por diversos motivos sentiam a influência da guerra, como o México e o Chile. Nesta primeira parte o interesse recai sobre a conformação de um campo aliadófilo e outro germanófilo com as diferentes estratégias de posicionamento entre os dois. Esses posicionamentos levaram grupos governantes terem que lidar com a Real Politik nas relações internas e internacionais, oscilando entre o neutralismo e a participação. Ao mesmo tempo, na primeira parte, analisa-se a construção da opinião pública em relação à guerra, com o posicionamento de intelectuais e políticos, mas também com a participação das coletividades de imigrantes. No caso argentino, os imigrantes terão uma voz potente sobre os acontecimentos de além-mar. Mas este é o momento fundante da constituição da opinião pública nacional. Certamente existiam grupos de ação política e intelectual, mas para a Argentina,trata-sedo momento de constituição de uma imprensa autônoma do poder econômico, no mesmo momento em 
que o Estado também inicia um processo de autonomização perante as oligarquias e o seu poder econômico e simbólico. A multiplicação das vozes e a emergência de novos atores, como os trabalhadores, colocará em questão a Real Politik, diferente do que acontecia no Brasil.

Na segunda parte do livro, "A Europa bárbara", temos outro tipo de aproximação do conflito. $\mathrm{O}$ autor avança em duas perspectivas complementares: a história da cultura e a das sensibilidades. A recepção do sofrimento e a expansão dos sentidos gerados por este sofrimento em relação à guerra, assim como as reflexões sobre seus horrores pela via da literatura testemunhal, como Barbusse, Aldous Huxley ou Erich Maria Remarque, levam a guerra ao plano do pessoal, ao sofrimento em primeira pessoa. Compagnon explora os impactos de reduzir o foco de análise por parte dos escritores e dos jornalistas, colocando em primeiro plano os civis e os soldados, fossem estes os próprios compatriotas que participavam na guerra ou as vítimas dos confrontos. Em princípio, para criar empatia com os bandos em disputa, mas também para apresentar o sofrimento em primeira pessoa, tentava-se criar uma corrente de opinião contrária ao conflito bélico. Aqui a Real Politik sai de cena. As pessoas de carne e osso mostravam os limites da civilização europeia e as suas pretensões de universalidade. O capítulo cinco,"A Noite Europeia”, um dos mais interessantes do livro, analisa os posicionamentos dos intelectuais brasileiros e argentinos acerca da Grande Guerra. O sentimento de inferioridade em relação aos feitos culturais europeus passam a ser questionados, a América pode ser modelo de si própria e para isso precisava realizar uma devassa da Europa. Rui Barbosa, José Ingenieros, Afrânio de Melo e Franco, entre outros pensadores e intelectuais,identificam esse período como o do declínio europeu. As interpretações podem ser diferentes, mas a América como contraponto de paz e civilidade são comuns. O binômio estabelecido por Domingo Sarmiento em meados do século XIX estava invertido: a América era a civilização e a Europa era a barbárie.

Compagnon explora os impactos de reduzir o foco de análise por parte dos escritores e dos jornalistas, colocando em primeiro plano os civis e os soldados

A última parte do livro, "A Grande Guerra, A Nação, A Identidade", é destinada a analisar os impactos culturais imediatos da Grande Guerra, enfocando o nacionalismo na Argentina e no Brasil. É esse o legado cultural e intelectual da Grande Guerra? É daqui que partem as famílias que se diferenciam do modelo Europeu? O que o autor vai explorar é o nacionalismo cultural anterior ao político. Para isso,Compagnon analisa as diversas vertentes desses nacionalismos, estabelecendo um estudo em paralelo de dois autores argentinos, Borges e Leopoldo Lugones, e o Movimento Antropofágico no Brasil. O contraponto permite acompanhar o impacto de longa duração nas gerações 
que vivenciaram o período de entre guerras: Borges e Lugones. O nacionalismo democrático e o autoritário. A renovação e a restauração, as duas correntes que, do campo intelectual, demarcariam territórios políticos por longo tempo.

A pesquisa realizada por Compagnon, especialista em história intelectual, mostra a necessidade de lidar com fontes de origens diferentes e com registros narrativos diversos para poder realizar uma síntese sobre a questão da Grande Guerra na América Latina. A história intelectual dialoga com a história política e cultural. A narrativa factual é necessária para públicos pouco familiarizados com a Grande Guerra ou com a América Latina para poder dar lugar a sofisticadas análises sobre a produção artística e literária latino-americana. Esperamos que o resultado seja o de estimular novas pesquisas deste tipo e com esta perspectiva.

A versão francesa do livro apresenta algumas diferenças da brasileira. A capa original foi trocada. A brasileira optou por uma previsível foto da guerra de trincheiras. A edição francesa reproduz a portada da partitura do tango $E l$ Marne, de Eduardo Arolas. A escolha é significativa e mostra os efeitos duradouros da guerra na cultura da região. Sem pretender ser exaustivo no forte impacto cultural da Grande Guerra na região, vou tentar mostrar a relação estabelecida com os círculos vinculados ao tango.

\section{A pesquisa mostra a necessidade de lidar com fontes de origens diferentes e com registros narrativos diversos para poder realizar uma síntese sobre a questão da Grande Guerra na América Latina}

Para isso, voltemos ao tango El Marne. Quando Eduardo Arolas compõe este tango era um jovem bandoneonista argentino, filho de franceses. Arolas teve a trajetória arquetípica de um tanguero do período. Nasceu em Barracas, na cidade de Buenos Aires, e morreu produto do alcoolismo,em Paris,aos 32 anos, longe da cidade que abandonou para fugir da relação estabelecida entre seu irmão e sua esposa. El Marne, escrito neste exílio voluntário, é uma peça que,mesmo sendo de profunda melancolia,entrou no repertório das grandes orquestras, parte do estilo do tango dançante por décadas. Escrito em 1919, este tango continua a receber novas versões e é frequentemente revisitado. Posteriormente e para ser mais palatável aos dançarinos, recebeu uma letra que falava de um amor a orilhas do Rio Marne, deturpando a sua origem vinculada a uma batalha com centenas de milhares de mortos, mas dando-lhe sobrevida.

Mas o tango e a Grande Guerra mantiveram o seu vínculo. Em princípio, porque a década de 1910 é o momento fundacional desse estilo musical. De fato, o grande ícone do tango, Carlos Gardel, escreveu um tango-canção para homenagear os combatentes franceses. Silencio foi escrito em 1932 e 
apresentado no filme Melodia de Arrabal, de 1933. O tango é claramente um manifesto antibélico. No filme, Gardel interpreta um cantante de tangos que, no palco que o consagraria, canta Silencio. O importante é a interpretação da letra: um melodrama. A letra faz referência a um caso, verdadeiro ou mítico pouco importa, de cinco irmãos operários que se alistam para lutar pela pátria, a França, e morrem. A mãe deles, la viejita, lamenta a morte dos filhos. Ela fica com os túmulos e as medalhas. A música começa com um clarim e um coro acompanha Gardel com uma canção de ninar. Quando conclui, ele, sorridente, abraça a sua namorada. Está consagrado, é um momento festivo. A Grande Guerra, na década de 1930, é uma temática que faz parte do universo narrativo. Ainda está presente, porém sem a carga dramática que tinha para Arolas. A guerra permaneceria no imaginário coletivo sobre o que podiam ser imprimidas imagens e sentimentos, como o sacrifício, a dor e a perda geradas pela guerra. Estes exemplos mostram o impacto de longa duração da guerra apresentado por Compagnon e que pode ser ampliado por novas pesquisas e novas perspectivas analíticas. Finalmente, essa pequena relação estabelecida entre o tango e a capa tem como objetivo mostrar a capacidade de síntese temática evidenciada na capa da edição francesa e a indefinição apresentada na capa brasileira, que confunde o leitor sobre os temas e as abordagens. 